Article

\title{
Energy Conservation Potential of Economizer Controls Using Optimal Outdoor Air Fraction Based on Field Study
}

\author{
Goopyo Hong ${ }^{1, *}$, Chul Kim ${ }^{2}$ and Jun Hong ${ }^{3}$ \\ 1 Department of Architectural Engineering, College of Engineering, Kangwon National University, \\ Samcheok 25913, Korea \\ 2 Department of Architecture, College of Architecture, Texas A\&M University, College Station, TX 77840, USA; \\ chulkim0503@gmail.com \\ 3 Department of Architectural Engineering, College of Engineering, Yonsei University, Seoul 03722, Korea; \\ hongjun84@hanmail.net \\ * Correspondence: goopyoh@kangwon.ac.kr; Tel.: +82-33-570-6526
}

Received: 2 September 2020; Accepted: 23 September 2020; Published: 24 September 2020

\begin{abstract}
In commercial buildings, HVAC systems are becoming a primary driver of energy consumption, which already account for $45 \%$ of the total building energy consumption. In the previous literature, researchers have studied several energy conservation measures to reduce HVAC system energy consumption. One of the effective ways is an economizer in air-handling units. Therefore, this study quantified the impact of the outdoor air fraction by economizer control type in cooling system loads based on actual air-handling unit operation data in a hospital. The optimal outdoor air fraction and energy performance for economizer control types were calculated and analyzed. The result showed that economizer controls using optimal outdoor air fraction were up to $45 \%$ more efficient in cooling loads than existing HVAC operations in the hospital. The energy savings potential was $6-14 \%$ of the differential dry-bulb temperature control, $17-27 \%$ of the differential enthalpy control, $8-17 \%$ of the differential dry-bulb temperature and high-limit differential enthalpy control, and $16-27 \%$ of the differential enthalpy and high-limit differential dry-bulb temperature control compared to the no economizer control. The result of this study will contribute to providing a better understanding of economizer controls in the hospital when the building operates in hot-humid climate regions.
\end{abstract}

Keywords: economizer; field study; cooling load; outdoor air fraction; energy saving; hospital

\section{Introduction}

In 2017, the building sector accounted for $20 \%$ of total energy consumption in Korea [1]. HVAC system (i.e., heating, cooling, and ventilation) is a primary driver of energy consumption in commercial buildings [2], which occupied about $45 \%$ of the total building energy use [3,4]. However, in most existing buildings, it is challenging to improve HVAC system performance due to the considerable construction costs of installing new systems. Thus, a proactive method of energy conservation would work for commercial buildings as the second-best plan to make a more efficient approach in air handling units (AHUs) [5].

In the literature, researchers studied various methods to improve efficiencies in the HVAC systems in operation stages, including the duty cycle, economizer, load reset, optimal start, optimal stop, and night purge [6-10]. Of them, one of the best ways to conserve energy is an economizer that introduces low-temperature or low-enthalpy outdoor air into the building to reduce or eliminate mechanical cooling depending on outdoor air conditions [11,12]. When outdoor air temperature (TOA) is lower 
than the supply air temperature (TSA), the economizer can provide free-cooling by introducing outdoor air. This can remove partial or complete mechanical cooling loads during intermediate seasons, and thus, HVAC system loads (e.g., chiller, pump, and cooling tower) can be reduced considerably [13]. In the process, outdoor air and return air can be modulated to produce optimal TSA and reduce mechanical cooling operations [14]. Therefore, if the air-handler operates the economizer effectively, significant amounts of energy savings [15,16], and the improved indoor air quality [17] are expected in commercial buildings [18].

Economizer control has significant energy saving potential in commercial buildings. Numerous studies recently explored the effect of diverse economizer control types on energy conservation [19-31]. Yao and Wang investigated the energy savings potential of temperature-based and enthalpy-based economizer cycles on VAV systems using a simulation program. They evaluated the energy-saving ratio using different controls of temperature-based and enthalpy-based economizer in six climate zones (i.e., cool-dry summer and very cold winter, moderate summer and cold winter, hot-dry summer and cold winter, hot-humid summer and mild winter, hot-humid summer and little cold winter, hot-humid summer and warm winter) in China. The result revealed that the economizer cycle in the hot-humid summer climate zones showed about 10-20\% energy savings compared to the cool-dry summer zone. This study identified that the climatic conditions are one of the significant factors affecting the energy-saving impact of air economizers [19]. Chowdhury and Khan calculated the effect of economizer control strategies based on return air temperature and pre-cooling in EnergyPlus and compared the simulated chiller energy consumption with measured data over five working days. The economizer controls in the simulation result reduced $72 \mathrm{~kW} / \mathrm{m}^{2}$ month in cooling loads than the existing building [20]. Son and Lee conducted an energy performance analysis of the economizer systems in an office building using EnergyPlus. To evaluate the cooling energy performance of the economizer cycle controls, the differential dry-bulb temperature (DT), differential enthalpy (DE), and no economizer (NE) methods were used in building energy simulations. The result suggested that the DT method could show less cooling energy savings than the DE method depending on TOA conditions, because latent heat is not considered in the DT method. In detail, the estimation of Incheon, Korea suggests that the DE control method showed the largest energy saving by approximately $10 \%$ under Korean climatic conditions compared to other economizer control methods. The DT control represented $12.7 \%$ smaller energy consumption than no economizer control in an intermediate period [21]. Similarily, Aktacir used a computer coding of the NE, DT, and DE economizer modes for simulations using a 15-year period of TOA data. This study identified that the DE economizer mode was the most energy conservative approach to save the cooling energy of the different economizer controls. Moreover, it worked effectively in March, April, October, and November in Mediterranean countries because they have hot and long summer. The rest of the year did not show cooling load savings [22]. Bulut used 16 years of bin data to determine the energy-efficient DT mode of economizer control types. The study analyzed the economic conditions and free cooling potential according to the TSA for an all-air HVAC system in different outdoor conditions. Moreover, the cooling hours and cooling energy costs were calculated when the TSAs were $15{ }^{\circ} \mathrm{C}, 18{ }^{\circ} \mathrm{C}, 21^{\circ} \mathrm{C}$, and $24^{\circ} \mathrm{C}$. The reduction rates in cooling energy costs were $10 \%, 18 \%$, and $25 \%$ compared to the TSA of $15^{\circ} \mathrm{C}$, respectively [15]. On the other hand, some researchers focused on optimization-based strategies [28] and damper controls [23] to improve the energy efficiency of economizer controls. As for building type, economizer controls have been applied in a variety of building types, such as data centers [24-27], office buildings [19,21], and residential homes $[28,29]$. However, case studies of hospitals are still uncommon in the field of economizer research.

The literature review verified the cooling energy savings potential from economizer controls in commercial buildings. However, most studies focused on data analysis from simulation programs and control methods (e.g., temperature-based, enthalpy-based control) to investigate economizer energy performance in residential buildings, office buildings, and data centers. The researchers neglected the outdoor air faction-based controls using field study data and the impact of economizer controls in 
the hospital. Without the data collection, it is difficult to realize accurate estimations of economizer performance and potential energy savings in different control types. Therefore, a study of optimal outdoor air fraction (OAF) can contribute to having a better understanding of free cooling using economizer cycles to alleviate mechanical cooling loads in transition seasons. This study aims to interpret operational data in the actual hospital building and analyze the effects of various economizer controls using optimal OAF. The results of this study can reveal energy conservation potential in the hospital.

To achieve the purpose of this study, the field data from AHUs in a large hospital in Korea were collected to observe the actual OAF in summer and the intermediary seasons. Based on the real operational data, the optimal OAF for economizer control types was calculated. In the process, energy performance was examined through high-limit control methods. These methods can calculate the optimum mixed air ratio according to the outdoor air conditions that focus on the TSA and the supply air enthalpy (SAE). The mechanical cooling hours and OAFs were used to compute the system loads of cooling coils by the economizer control types and then compared the results with the actual operation and the NE control mode to quantitively compare the energy conservation effect in economizers. The data for economizer analysis were selected from March to November in 2016, which corresponds to the spring, summer, and fall in Korea.

The research procedure is briefly shown in Figure 1. Section 2 describes the economizer control types and the optimal outdoor air fraction calculation methods for each control type. Section 3 introduces a case study building and its HVAC systems, and then demonstrates how to acquire building operation data from the air-handling units through the sensors. In Section 4, the temperature distribution in the air-handing units is analyzed, and the outdoor air fraction is calculated using the actual operation data. Based on the optimal outdoor air fraction calculations, system cooling coil loads of four types of economizer controls were estimated and compared to compute potential energy savings in the hospital. The results of this study can contribute to the development of an energy-efficient HVAC driving method by interpreting actual building driving data for spring, summer, and fall when economizers are applied during the year in hot-humid climate zones. Moreover, recently, researchers have attempted to advance building system controls and algorithms using a variety of energy management platforms; thus, based on the outcome of this study, if the economizer can be integrated with such approaches, the economizer control methods would be more sophisticated and elaborate in HVAC systems.

\begin{tabular}{|c|}
\hline $\begin{array}{c}\text { Economizer Control Types } \\
\text { (Section 2) }\end{array}$ \\
\hline \hline Definition by Control \\
Methodology for \\
Calculation of Optimal OAF \\
by Control \\
\hline
\end{tabular}
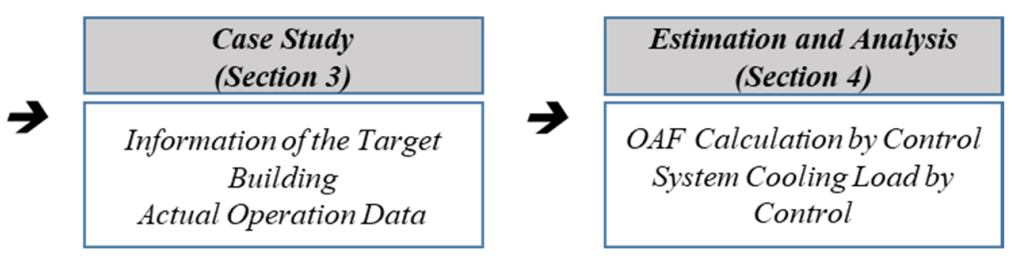

Figure 1. The procedure of the research.

\section{Outdoor Air Fraction (OAF) Estimation of Economizer Control Types}

An economizer cycle is a part of the air conditioning cycle that uses cool outside air for free-cooling or to chill the condenser water in a cooling tower (or an evaporative cooler) so as to maintain a space set-temperature [15]. The performance of economizer cycles is closely related to the external air fraction depending on outdoor conditions. Therefore, this chapter investigated OAF calculation methods in different economizer controls. With previous literature and ASHRAE 90.1-2019 [30], this study selected the representative economizer control types, including high-limit controls, to evaluate the energy potential savings by optimal OAF. These economizer control types are as follows:

- $\quad$ Single-parameter control: Differential dry-bulb temperature (DT)

- $\quad$ Single-parameter control: Differential enthalpy (DE) 
- Multi-parameter control: Differential dry-bulb temperature and differential enthalpy (DTDE)

- Multi-parameter control: Differential enthalpy and differential dry-bulb temperature (DEDT)

For this study, the OAF is defined as the ratio of the outside air intake rate to the total amount of air delivered by the AHU system. The minimum OAF was determined at $30 \%$ based on the standards in $[31,32]$. In the analysis, NE mode is considered to represent minimum OAF operations in AHUs. This can be used as a baseline to compare energy performance with different economizer control types. Figures $2-5$ show the economizer control types and the equations for calculating optimal OAF.

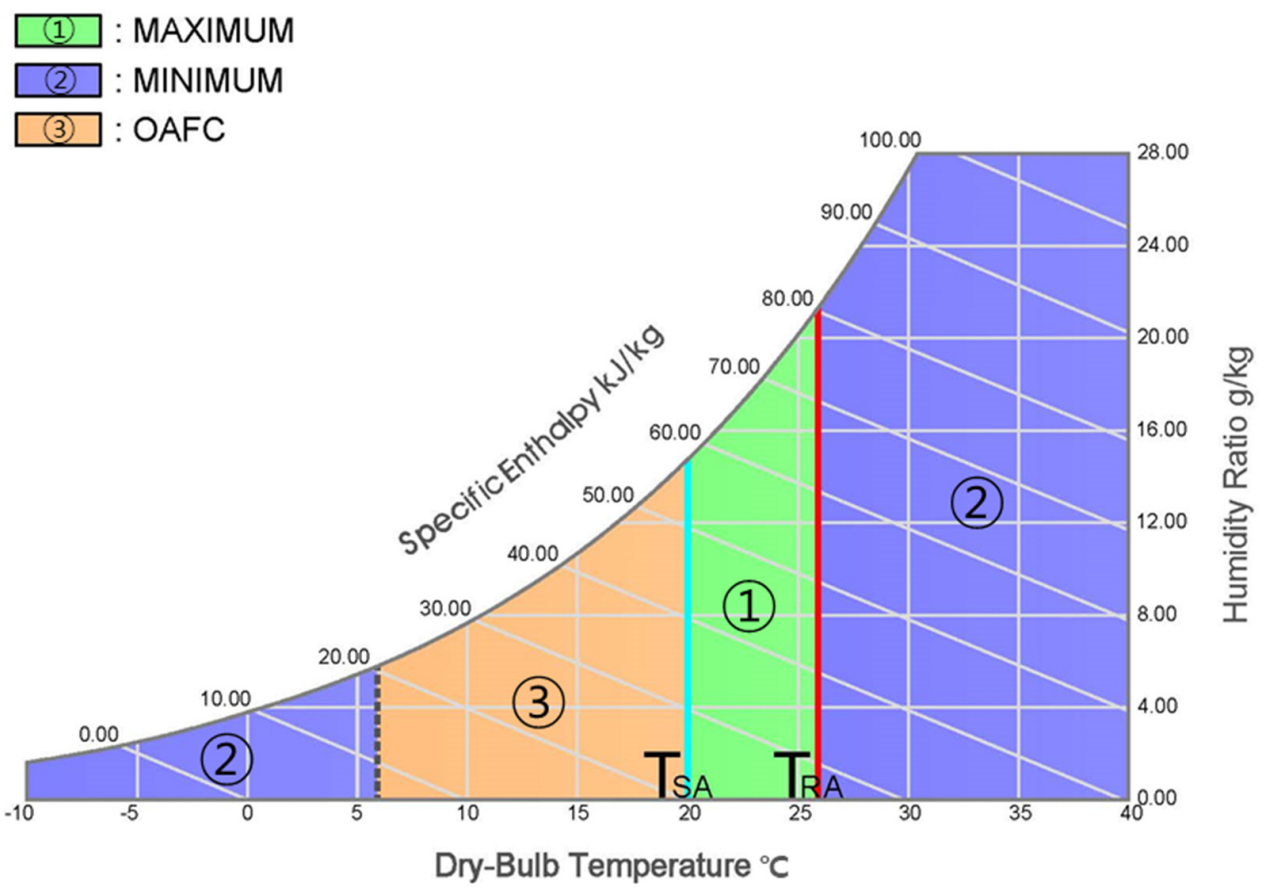

Figure 2. Differential dry-bulb temperature control method.

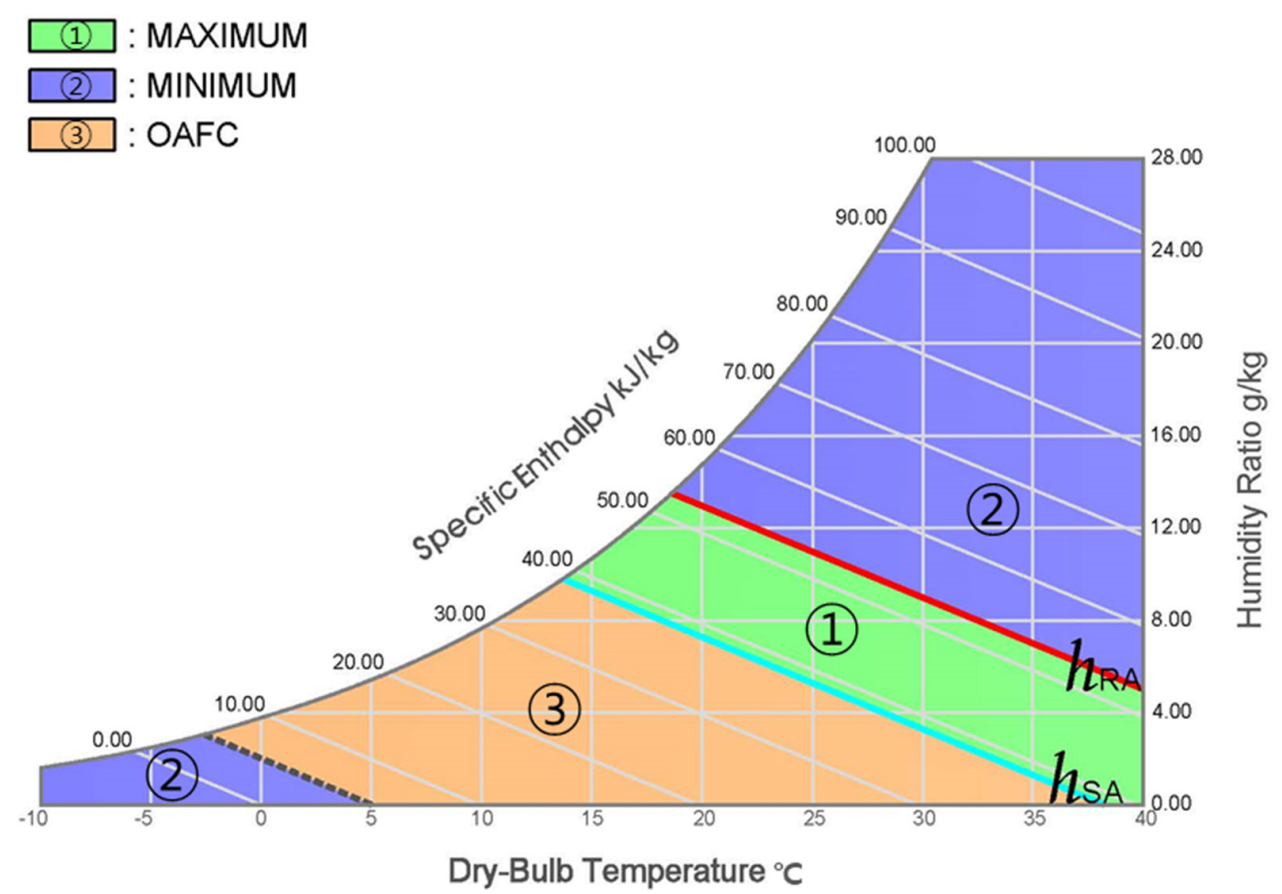

Figure 3. Differential enthalpy control method. 

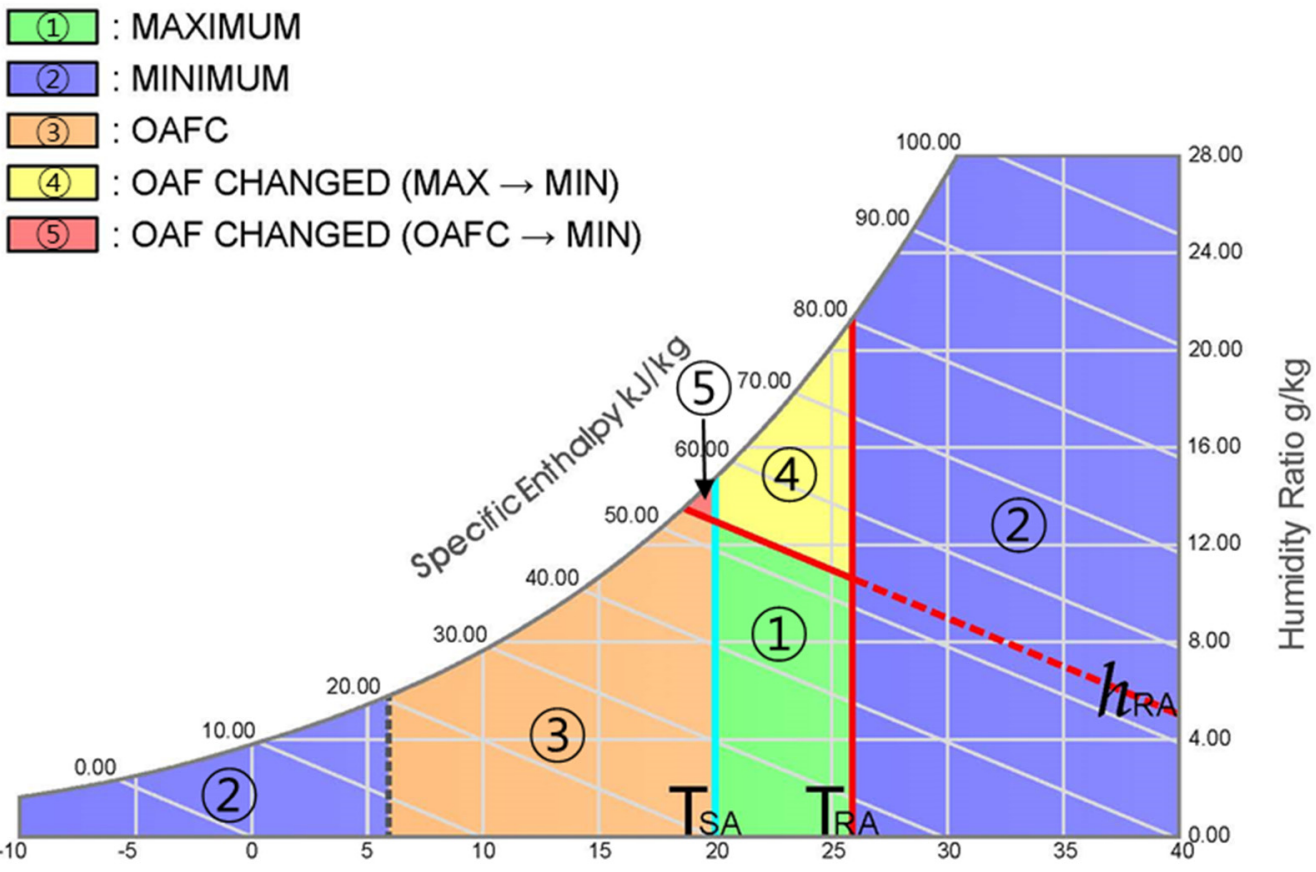

Dry-Bulb Temperature ${ }^{\circ} \mathrm{C}$

Figure 4. Differential dry-bulb temperature and enthalpy control method.

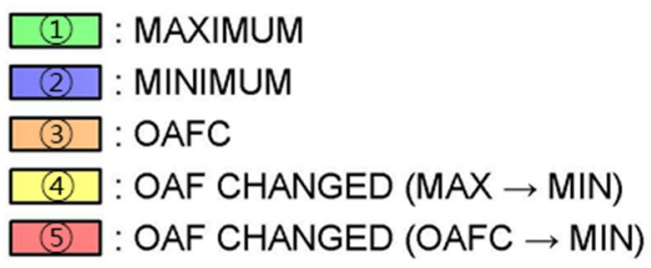

(3)

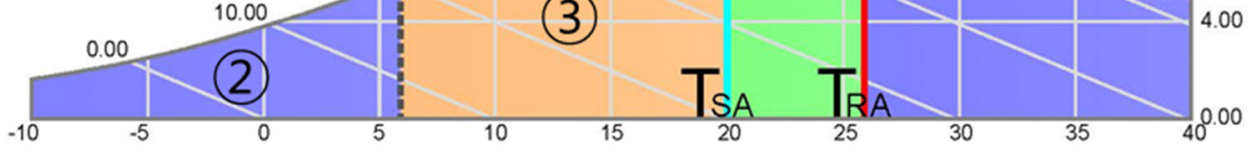

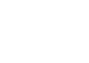


be represented on the psychrometric chart in various ways, and the TOA locations are categorized according to colors and numbers, as shown in Figure 2.

It is assumed that if the TOA is $0{ }^{\circ} \mathrm{C}$, the OAF is set to $30 \%$. The minimum OAF boundary point occurs when the TOA is $6^{\circ} \mathrm{C}$ (black dashed line). The minimum outdoor airflow is supplied when the TOA falls below $6{ }^{\circ} \mathrm{C}$ (area (2)). The optimal OAF is calculated with Equation (1) when the TOA is from $6{ }^{\circ} \mathrm{C}$ to $20^{\circ} \mathrm{C}$ (area (3), OAFC: outdoor air fraction calculation). When the calculated outdoor airflow is supplied in area (3), there is no need for mechanical cooling. In cases where the TOA is higher than the TSA (area (1)), the OAF is at its maximum (100\%). Thus, the mixed air temperature (TMA) is set to the same temperature as the TOA. Mechanical cooling is needed in area (1). In the area where the TOA is higher than the TRA, the OAF is at its minimum; this is categorized in area (2) to the right of Figure 2. Next is the equation to calculate the optimal OAF in area (3).

$$
\mathrm{OAF}=\frac{T_{R A}-T_{S A}}{T_{R A}-T_{O A}}
$$

where $\mathrm{OAF}=$ outdoor air fraction, $T_{R A}=$ return air temperature, $T_{S A}=$ supply air temperature, and $T_{O A}=$ outdoor air temperature.

\subsection{Differential Enthalpy (DE) Control}

The DE control method compares outdoor air enthalpy (OAE) to return air enthalpy (RAE). If the OAE is lower than the RAE, outdoor air is desirable for eliminating or reducing the cooling loads in a mixed chamber in AHUs. Figure 3 shows the scheme of the psychrometric chart for the DE control method.

Using the same concept as the DT method, enthalpy is used instead of temperature. If the RAE and the SAE are $53 \mathrm{~kJ} / \mathrm{kg}$ (dry-bulb temp.: $26^{\circ} \mathrm{C}$, humidity ratio: $10.5 \mathrm{~g} / \mathrm{kg}$ ) and $38.5 \mathrm{~kJ} / \mathrm{kg}$ (dry-bulb temp.: $20^{\circ} \mathrm{C}$, humidity ratio: $7.3 \mathrm{~g} / \mathrm{kg}$ ), respectively, then when the OAE is lower than the SAE (area (3)), the optimal OAF can be calculated using Equation (2). In this case, additional mechanical cooling is not necessary. If the OAE is in between the RAE and the SAE (area (1), the OAF is the maximum, and the least amount of mechanical cooling is required. As for energy conservation, although the closed damper of outdoor air is the best when the OAE is much lower or higher (area (2) than the RAE, the minimum OAF is maintained for the sake of indoor air quality. Equation (2) was used to calculate the optimal OAF for area (3) (OAFC: outdoor air fraction calculation), as Figure 3 shows.

$$
\mathrm{OAF}=\frac{h_{R A}-h_{S A}}{h_{R A}-h_{O A}}
$$

where OAF = outdoor air fraction, $h_{R A}=$ return air enthalpy $(\mathrm{kJ} / \mathrm{kg}), h_{S A}=$ supply air enthalpy $(\mathrm{kJ} / \mathrm{kg})$, and $h_{O A}=$ outdoor air enthalpy $(\mathrm{kJ} / \mathrm{kg})$.

\subsection{Differential Dry-Bulb Temperature + Differential Enthalpy (DTDE) Control}

The DTDE is a multi-parameter control method, which uses a combination of the high limit controls. After considering differential dry-bulb temperature (like the DT method), it uses a high limit control of the RAE. In Figure 4, area (4) should introduce 100\% of the OAF if only the DT control is taken into account. However, when considering the enthalpy high limit control, the minimum outside air $(30 \%)$ must be introduced. Thus, even though the TOA is lower than the TRA, it is changed to the minimum OAF, because the OAE is higher than the RAE. Since the TOA of the area (5) is lower than the TSA, in the DT method, the maximum of the OAF can be calculated using Equation (1). However, in the DTDE method, the OAF of the area (5) in Figure 4) should consider the enthalpy high limit control, and the minimum OAF is more energy conservative. In this case, the temperature may be satisfactory, but due to the high humidity, the latent heat load increases. Thus, the optimal OAF should be the minimum OAF. 


\subsection{Differential Enthalpy + Differential Dry-Bulb Temperature (DEDT) Control}

The differential enthalpy + differential dry-bulb temperature (DEDT) control is conceptually similar to the DTDE method described above, but it is different in the control sequence. Figure 5 shows that it uses enthalpy as a base, and sets the TRA high limit control. If the RAE and the SAE are $53 \mathrm{~kJ} / \mathrm{kg}$ (dry-bulb temp: $26^{\circ} \mathrm{C}$, humidity ratio: $10.5 \mathrm{~g} / \mathrm{kg}$ ) and $38.5 \mathrm{~kJ} / \mathrm{kg}$ (dry-bulb temp: $2{ }^{\circ} \mathrm{C}$, humidity ratio: $7.3 \mathrm{~g} / \mathrm{kg}$ ), respectively, and if the OAE is lower than the SAE (area (3)-OAFC: outdoor air fraction calculation), the optimal OAF can be calculated using Equation (2). In this case, additional mechanical cooling is not considered. If the OAE is in between the RAE and the SAE (area (1)), the OAF should be its maximum value, and the minimum amount of mechanical cooling is needed. Thus, $100 \%$ of outdoor air is advantageous in energy use. In this control method, because of the TOA conditions for two areas (4) and (5)), the OAF changes from maximum OAF to minimum OAF. From an enthalpy point of view, the maximum OAF can be maintained, but because of the TRA high-limit control, it is changed to the minimum OAF. The DEDT control typically has less energy-saving potential than DE control. However, it is significant to quantify the changes in system loads compared to the DE control.

\section{Data Collection and Processing}

\subsection{Case Study Building}

The current study analyzed the energy savings potential of different economizer controls using the field study data from a hospital building. A case study building is a fifteen-story hospital with six basement floors in Seoul, Korea. The total building area is about $105,800 \mathrm{~m}^{2}$, and the height is approximately $80 \mathrm{~m}$ high. The case study building complied with the Energy Saving Design Standards of Buildings in Korea, and the thermophysical properties of the envelope are described in Table 1. This study investigated the economizer controls using AHU operational data of the patient rooms in the hospital. The air-conditioning systems of patient rooms are interconnected VAV systems and convectors for heating and cooling. Figure 6 shows the thermal zones of patient rooms in the case study building. Four zones were designed according to building orientations (i.e., south, southwest, southeast, and north), and assigned to five floors of the patient rooms to efficiently operate the heating and cooling systems. In terms of AHUs, four AHUs (i.e., AHU1-4, Air-handling units of the case study building are described in Table 2.) are in charge of each zoning in five floors from the 9th to the 13th floor in the hospital. In other words, AHU 1 operates cooling and heating systems for the wards from the 9th to the 13th floor in the south, and the AHU 2 covers the air conditioning of the wards from the 9th to the 13th floor in the southwest. In this study, the temperature, humidity, and fan supply air of four AHUs were measured by building facility managers, and then the collected data were used to calculate the outside air intake ratio and to analyze the system cooling loads. The operation data were directly collected from hospital facility managers. The actual data were used in this study to understand the actual operations in each AHU, and the evaluations of economizer performance were conducted to calculate the different effects of economizer control types.

Table 1. Thermophysical properties of the case study building.

\begin{tabular}{|c|c|c|c|}
\hline & $\begin{array}{l}\text { Thermal Transmittance } \\
\qquad\left(\mathrm{W} / \mathrm{m}^{2} \mathrm{~K}\right)\end{array}$ & $\begin{array}{l}\text { Code Compliance } \\
\qquad\left(\mathrm{W} / \mathrm{m}^{2} \mathrm{~K}\right)\end{array}$ & Construction (Outside to Inside) \\
\hline Wall & 0.37 & 0.40 & $\begin{array}{l}\text { Aluminum panel, } 80 \mathrm{~mm} \text { glass wool, } \\
200 \mathrm{~mm} \text { normal concrete }\end{array}$ \\
\hline Roof & 0.25 & 0.29 & $\begin{array}{c}60 \mathrm{~mm} \text { normal concrete, XPS insulation } \\
110 \mathrm{~mm}\end{array}$ \\
\hline Floor & 0.38 & 0.58 & $\begin{array}{l}\text { Finish, } 80 \mathrm{~mm} \text { glass wool, } 150 \mathrm{~mm} \\
\text { normal concrete }\end{array}$ \\
\hline Window & 3.40 & 3.84 & Glass $(6 \mathrm{~mm})$, air $(12 \mathrm{~mm})$, glass $(6 \mathrm{~mm})$ \\
\hline
\end{tabular}




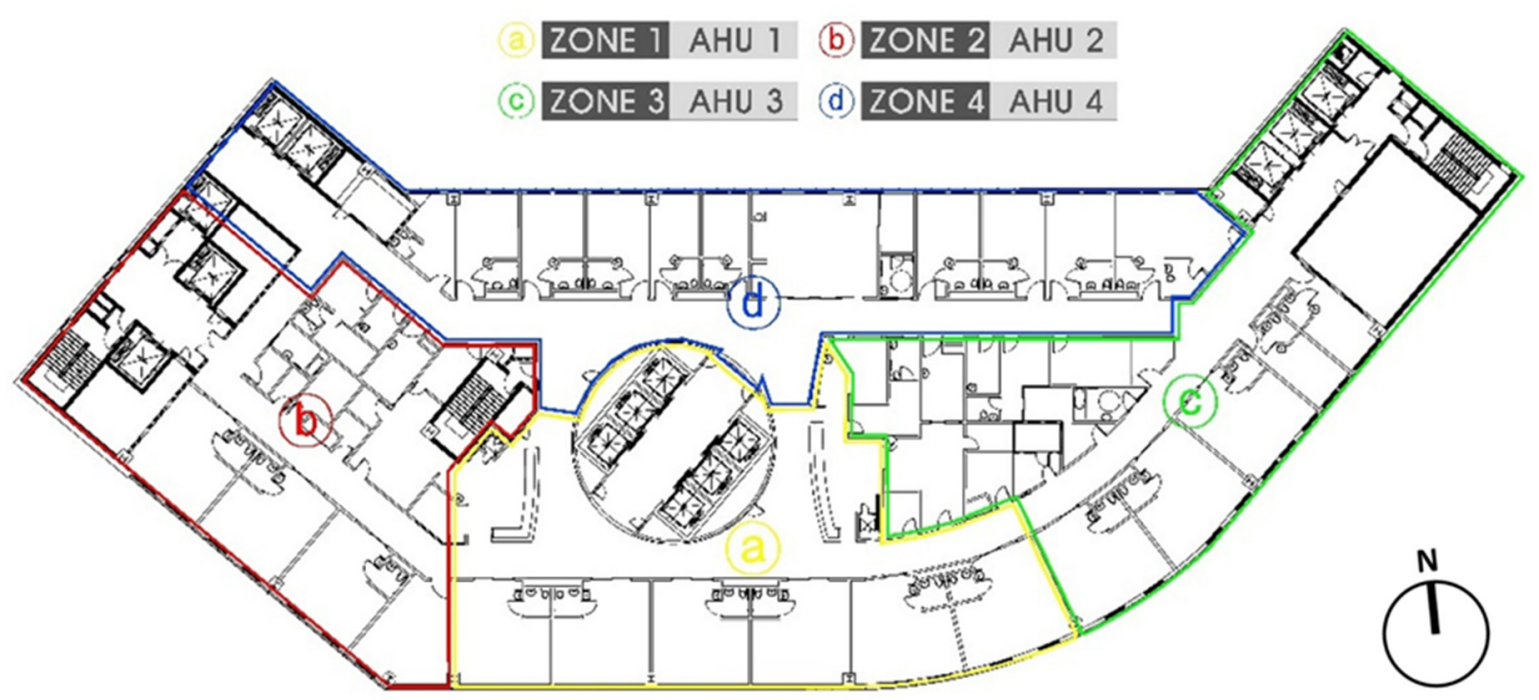

Figure 6. Case study building: typical floor plan and thermal zoning.

Table 2. Air-handling units of the case study building.

\begin{tabular}{|c|c|c|c|c|c|}
\hline & & AHU 1 & AHU 2 & AHU 3 & AHU 4 \\
\hline \multicolumn{2}{|l|}{ Zoning } & $\begin{array}{l}\text { Southern zone } \\
\text { (zone 1) }\end{array}$ & $\begin{array}{l}\text { Southwestern } \\
\text { zone (Zone 2) }\end{array}$ & $\begin{array}{l}\text { Southeastern } \\
\text { zone (Zone 3) }\end{array}$ & $\begin{array}{l}\text { Northern zone } \\
\quad \text { (Zone 4) }\end{array}$ \\
\hline \multicolumn{2}{|l|}{ Location } & $9 \mathrm{~F}-13 \mathrm{~F}$ & 9F-13F & $9 \mathrm{~F}-13 \mathrm{~F}$ & $9 F-13 F$ \\
\hline \multicolumn{2}{|l|}{ Space Type } & Patient room & Patient room & Patient room & Patient room \\
\hline \multicolumn{2}{|c|}{ Number of beds (rooms) } & $120(31)$ & $65(19)$ & $72(19)$ & $108(27)$ \\
\hline \multicolumn{2}{|c|}{ Area $\left(\mathrm{m}^{2}\right)$} & 2647 & 2286 & 2026 & 2880 \\
\hline \multirow{4}{*}{ Area Usage } & Patient Room (\%) & 49 & 31 & 39 & 39 \\
\hline & Office $(\%)$ & 0 & 6 & 6 & 0 \\
\hline & Treatment Room (\%) & 41 & 26 & 24 & 21 \\
\hline & Common Area (\%) & 10 & 37 & 32 & 40 \\
\hline
\end{tabular}

\subsection{Data Collection}

The data collection was performed in December 2015 to November 2016 from different types of sensors mounted in the AHU systems of patient rooms. Figure 7 shows the actual AHU system and the computer screenshot of the monitoring and operating systems in the central control room of the case study building. We collected the data of temperature (i.e., indoor air, outdoor air, supply air, return air, mixed air), relative humidity (i.e., indoor air, outdoor air, supply air, return air), airflow rate (i.e., supply air, return air), pressure difference, coil valve opening ratio (i.e., heating, cooling), and indoor carbon dioxide. Table 3 shows information of the sensors mounted in the AHUs. Based on the data collection, the current study analyzed the impact of economizer controls using the optimal OAF from different aspects, including (1) diagnosis of actual building OAF, (2) optimal OAF calculations, and (3) estimations of system cooling loads and free-cooling savings potential. Based on measured temperatures (i.e., indoor air, outdoor air, supply air, return air, mixed air) and relative humidity (i.e., indoor air, outdoor air, supply air, return air), enthalpy values were calculated to develop enthalpy-based control models (i.e., DE, DEDT). OAFs by economizer control types were determined using the above equations. 


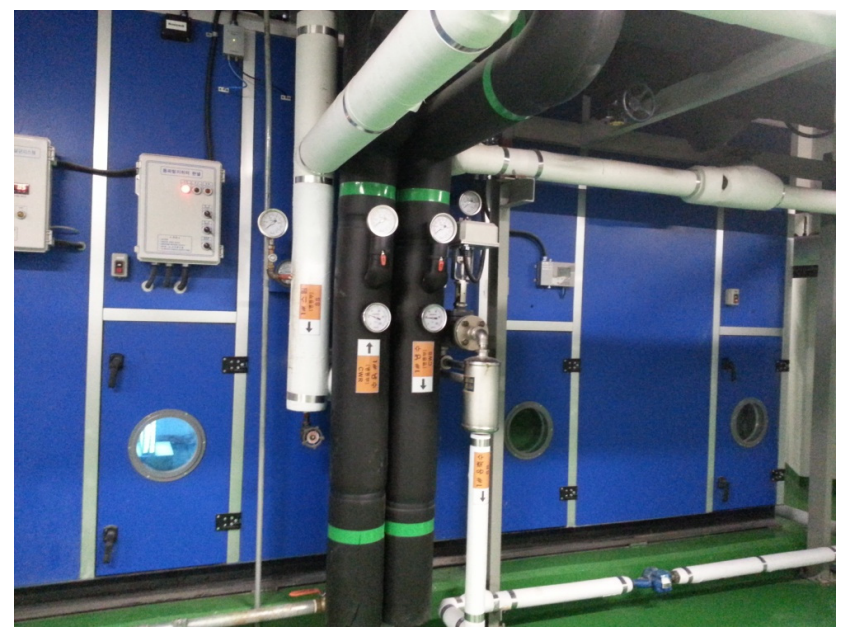

(a) Case building AHU

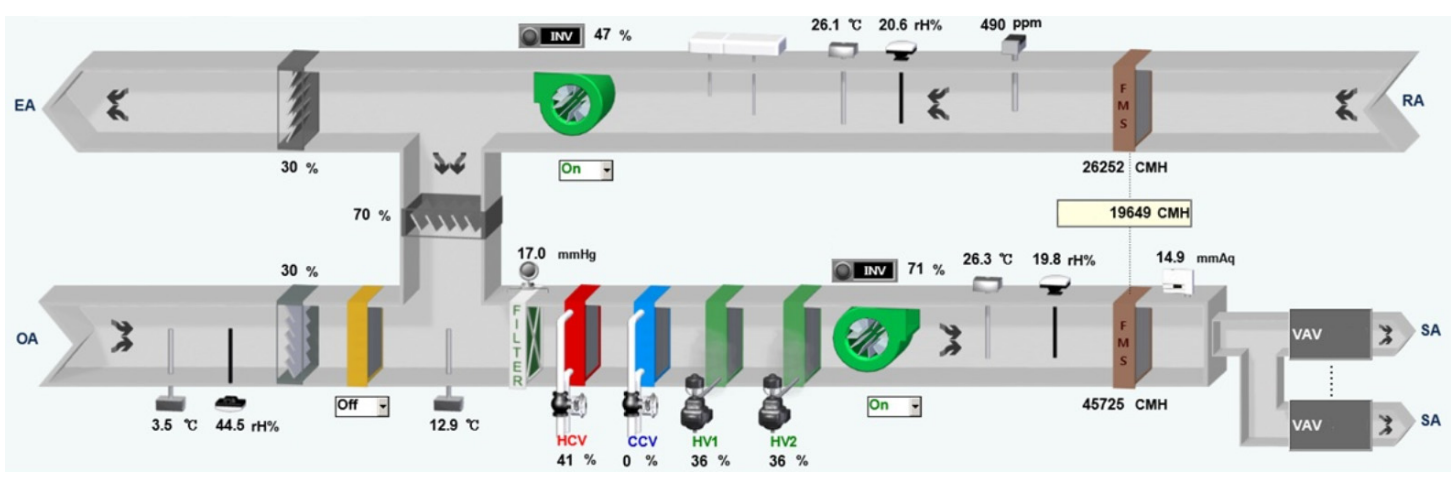

(b) Monitoring and operation system

Figure 7. HVAC systems: (a) Case building AHU and (b) Monitoring and operation system.

Table 3. Sensors mounted in the AHU.

\begin{tabular}{cccc}
\hline & Model & Measuring Range & Measuring Accuracy \\
\hline Temperature & QAM2171.044 & $-50{ }^{\circ} \mathrm{C}$ to $+50{ }^{\circ} \mathrm{C}$ & $\pm 0.75 \mathrm{~K}$ \\
Relative Humidity & QFM81.21 & $15 \%$ to $95 \%$ & $\pm 4 \%$ \\
Pressure & QBE2103-P10 & $0-1.0 \mathrm{MPa}$ & $\pm 0.25 \%$ \\
\hline
\end{tabular}

\section{Results}

With using the actual building operational data to estimate cooling energy savings potential from economizer controls, this study investigated the optimal OAFs of the four economizer control types in AHUs. The OAFs were calculated for all control types, including the NE and actual operations. The system loads for each control type were projected based on the estimated OAFs. The result of the system loads demonstrated a significant possibility in cooling load savings in the hospital, depending on the control operation modes in economizer.

\subsection{Outdoor Air Fraction of the Case Study Building's AHU}

A dataset of the OAFs, shown in Table 4, represents actual outdoor air fraction data of AHU 1 from March to November. In spring, actual OAFs are 39-60\%, and in summer, the OAFs was 43-74\%. The OAFs of fall were $49 \%$ to $70 \%$ in 2016 . The seasonal OAF average was $52-59 \%$ throughout the monitored period. Figure 8 shows the OAFs, the mean TOA, the mean TSA, and the mean TRA of 
the case study building by season. The cooling setpoint temperature in the hospital was $26^{\circ} \mathrm{C}$ for the season. The indoor air temperature was kept constant at an average of $26^{\circ} \mathrm{C}$.

Table 4. Monthly average outdoor air fraction (OAF) in the case study.

\begin{tabular}{cccccccccc}
\hline Contents & Mar & Apr & May & Jun & Jul & Aug & Sep & Oct & Nov \\
\hline OAF (\%) & 39 & 56 & 60 & 74 & 61 & 43 & 70 & 50 & 49 \\
Season Avg. (\%) & & 52 & & & 59 & & & 56 & \\
\hline
\end{tabular}

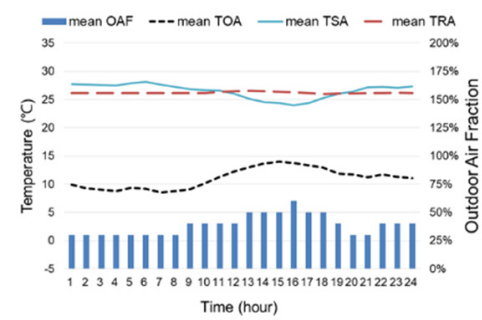

(a) March

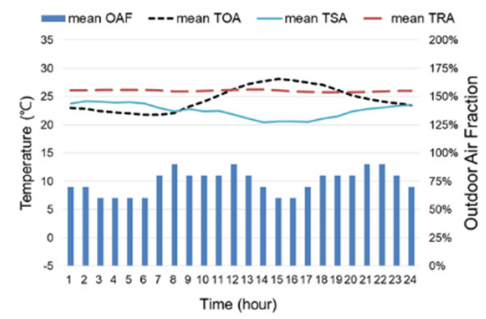

(d) June

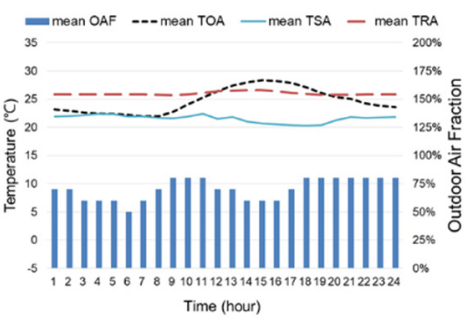

(g) September

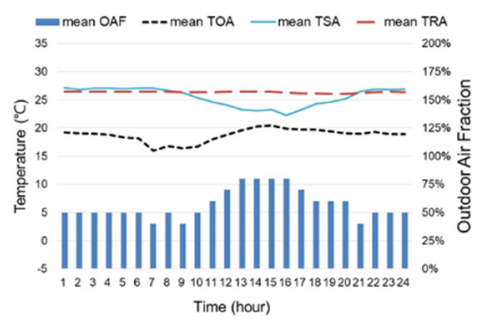

(b) April

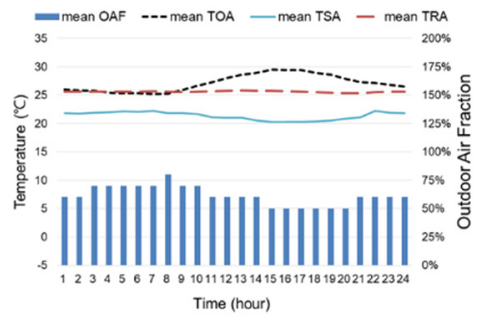

(e) July

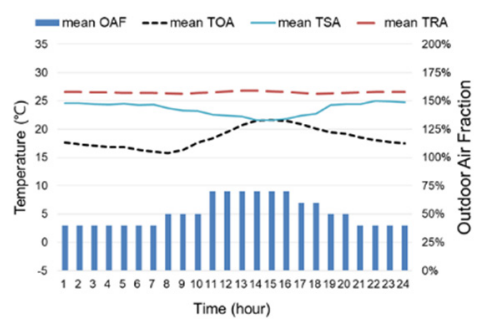

(h) October

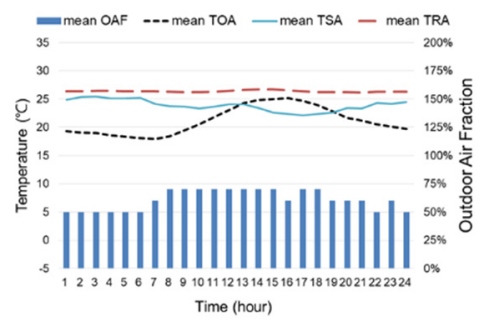

(c) May

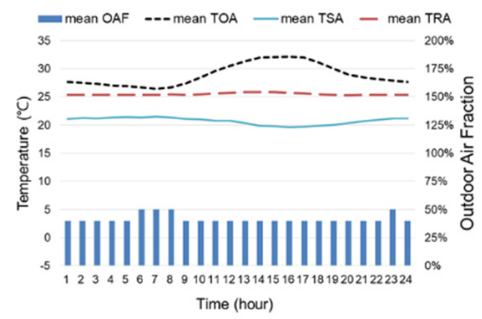

(f) August

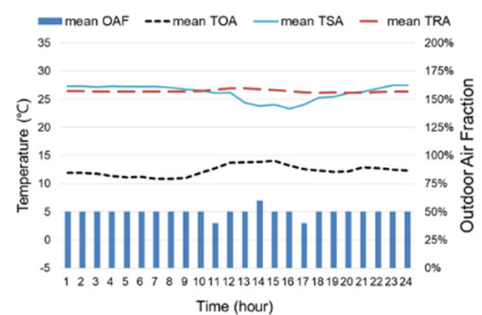

(i) November

Figure 8. OAF and temperature distribution (March to November).

In Figure $8 \mathrm{a}-\mathrm{c}$, there was a pattern of the OAF that showed low fractions at night time in spring when the TOA was low. Moreover, the OAF increased during the day as the TOA increased and the TSA was low. However, the OAF was relatively consistent in May, when the TOA was higher than the TSA. Figure $8 \mathrm{~d}-\mathrm{f}$ shows the monthly averages of the OAF and temperature distribution in summer. The OAF was the lowest if the TOA became higher than the TSA and TRA. Since the distribution of TOA was mostly higher than the TSA and the TRA during August, the OAF was fixed at the minimum value. In September, the OAF increased when the TOA was lower than the TRA, as shown in Figure 8g-i. When the TOA is higher than the TRA, it is necessary to maintain the minimum OAF. In the graph, this means that the OAF was continuously kept low. In October, the distribution patterns of the OAF and the TOA were similar in trends. In November, the overall OAF was lower than in October.

Briefly, in the plots of the TOA and the OAF by month, the OAF is constantly fluctuating depending on whether the TOA and the TSA are higher or lower than the TRA. In the spring and fall, when the TOA is lower than the TRA, free cooling is possible instead of mechanical cooling operations according to the appropriate OAFs. Therefore, to support effective economizer operations, the calculation of the 
optimal OAF is important-considering the TSA, and not merely comparing the TOA and the TRA for economizer controls.

\subsection{Optimal Outdoor Air Fraction (OAF) by Economizer Control Types}

In this chapter, the optimal OAF of different economizer control types was calculated using operational data in AHU 1 and the Equations (1) and (2). The OAF is very significant in economizer performance calculations to reduce gaps between the TSA and SAE and the TMA and the mixing enthalpy (MAE). If the TSA and SAE are equal to the TMA and MAE, the system cooling loads will be zero. Therefore, many parts of economizer controls depend on the OAF calculations to match the TSA and SAE and the TMA and MAE as much as possible, which could provide improved energy efficiency in HVAC systems to reduce wasted cooling energy.

Figure 9 represents actual OAF from the case study building and the calculated optimal OAF by economizer control types. The estimated OAF of different control types was compared with actual operation OAF data (Actual) and no economizer (NE) mode. In spring, the trend of the OAF was a steady increase from March to May in four control types. The OAF for the actual operation was 39\% in March, and the OAF for the control types was 31-33\%. April and May introduced 10-20\% more outdoor air, compared to March. In summer, the pattern of the OAF was a gradual decrease from June to August except the NE control. The actual operation data from the building was the highest compared to all control types, and the DT control introduced the largest amount of outdoor air among control types. The range of actual OAF in summer was $43 \%$ to $74 \%$, and the OAF of economizer controls was $33 \%$ to $64 \%$ between control types. In the summer season (e.g., July, August), it is difficult to use free cooling due to the high outside air temperature and enthalpy. In the fall, the OAF pattern from September to November declined, which was similar to the summer. The OAF of the actual operation changed $49 \%$ to $70 \%$, and the economizer controls showed the range of $31 \%$ to $63 \%$.

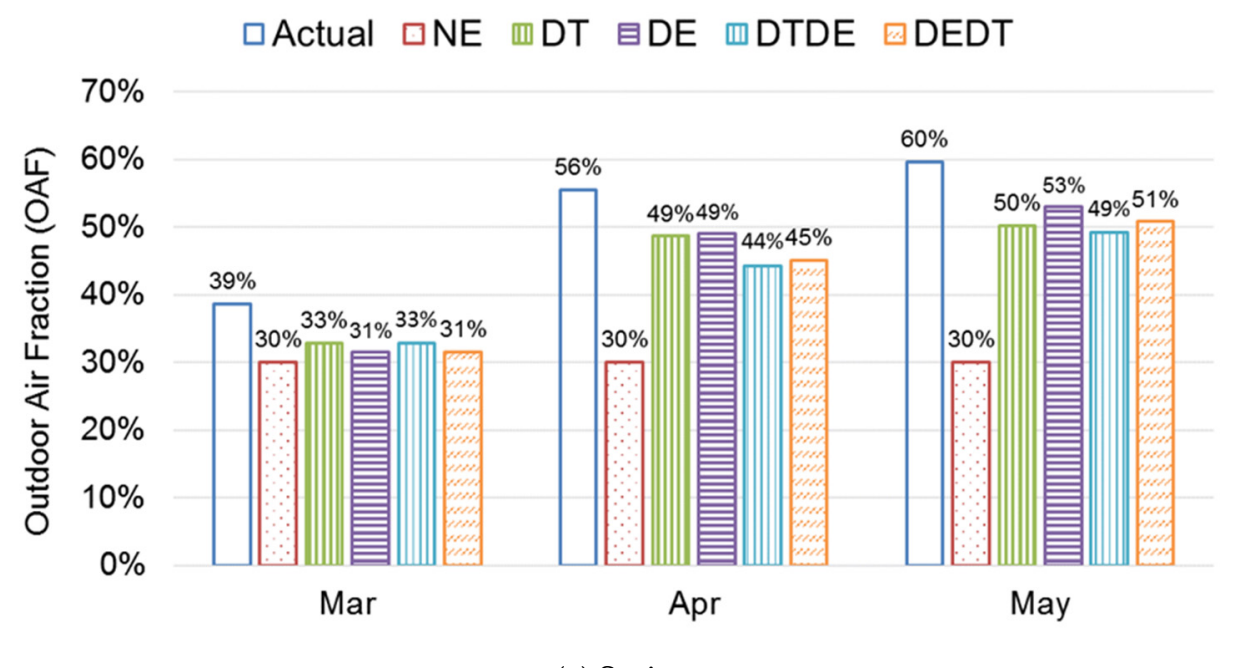

(a) Spring

Figure 9. Cont. 


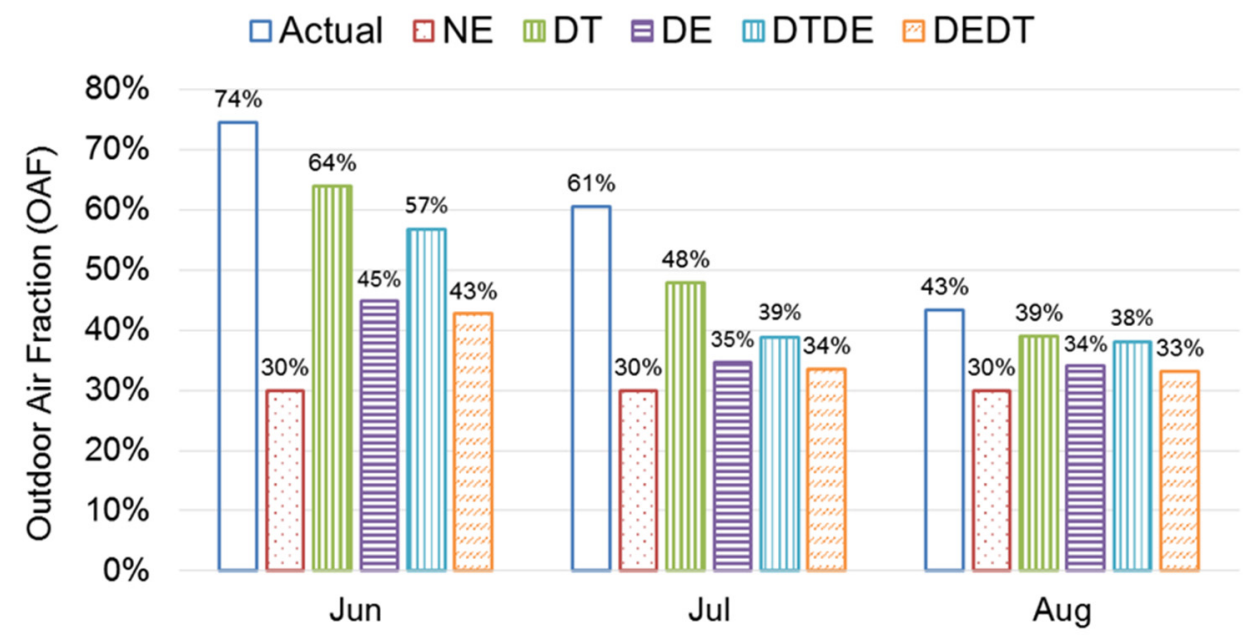

(b) summer

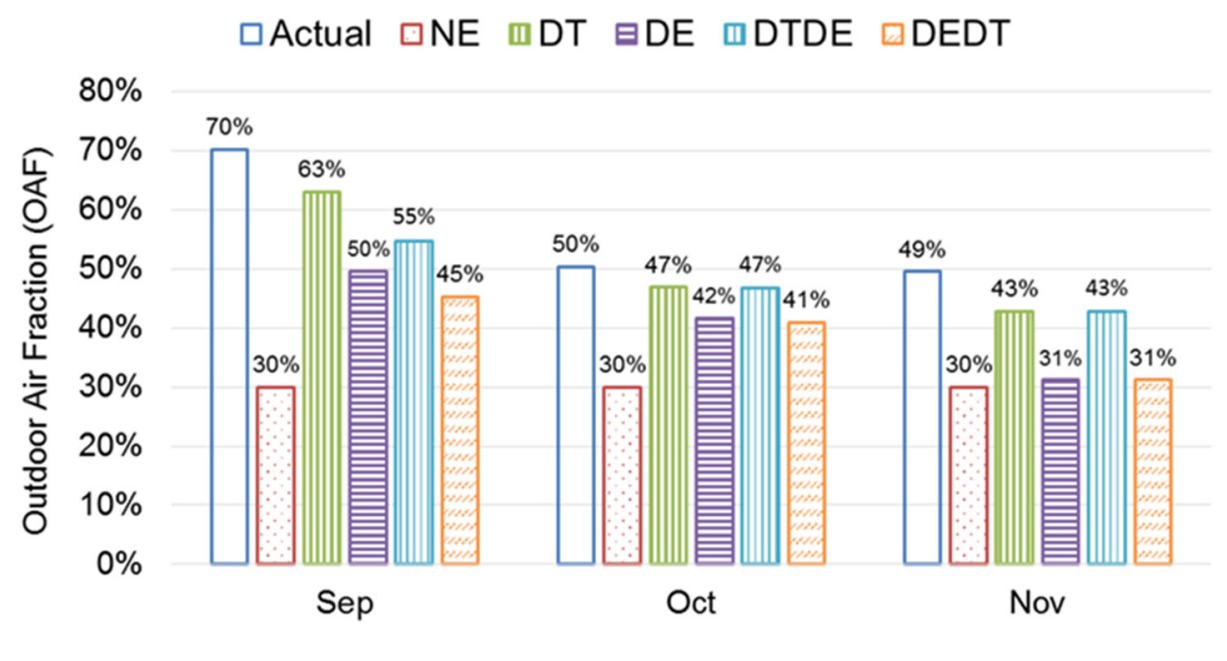

(c) Fall

Figure 9. Average outdoor air fraction by season and control types.

In a comparison of OAF between different economizer control types, the proportion of the OAF was highest in the DT control. The DT control method in spring represented a similar distribution with the DE control. However, in summer, the DT control method showed the highest values in June. The distribution rate of the OAF lowered in July and August compared to spring. In fall, the highest OAF was during September.

From the AHU data, in May and September, the economizers showed the highest free cooling potential. The OAF of the actual operation was 3-13\% higher than other economizer control types in spring to fall. The results of the optimal OAF demonstrate that each control type had different OAFs depending on the seasonal change from March to November. Based on the OAF calculations, the system cooling loads were estimated, and the most energy-efficient control type was analyzed. This is significant to analyzing actual building operation status with economizers quantitatively, which can be used to calculate potential energy savings in the cooling coils and propose the most energy-efficient economizer control type in the hospital. 


\subsection{System Loads by Control Types}

This study calculated cooling coil loads at the system level. Free cooling using an economizer can reduce the waste of cooling energy from spring to fall. The optimal OAF of economizer controls highly contributed to the cooling coil load savings of HVAC systems in the studied building. In calculations, the effect of the economizer cycle varied depending on the control types. Free cooling is available with economizer systems if the TMA or the MAE meets the TSA or the SAE. According to the changes to the OAF in different economizer control types, the amount of the MAE changes. To estimate energy performance in the economizer, Equation (3) is used to calculate the system loads based on the difference between the MAE and the SAE.

$$
\text { System load }(\mathrm{kW})=\rho \times \mathrm{Q} \times \Delta h \div 3600
$$

where $\rho=$ air density $\left(\mathrm{kg} / \mathrm{m}^{3}\right), \mathrm{Q}=$ air flow rate $\left(\mathrm{m}^{3} / \mathrm{h}\right)$, and $\Delta h=$ difference of enthalpy $(\mathrm{kJ} / \mathrm{kg})$

Figure 10 shows the calculated system cooling loads of AHU 1 on the monthly average by control types, including actual operation and the NE control. In spring, the DE control method showed a very small system cooling load in April. Thus, for the case study in April, the DE control method can be used effectively to gain the greatest reduction in cooling energy consumption. The actual system cooling loads of AHU 1 from March to May were 49.7 MWh. In spring, the cooling system loads for the DE method were 9.7 MWh, which can save five times more energy than the actual operation. The NE control showed that $55 \mathrm{MWh}$ was the highest system cooling load. Thus, in spring, the NE control used roughly six times more cooling energy than the DE control. Among the economizer control methods, the DE method, which uses enthalpy control, was the best energy conservation system for the hospital.

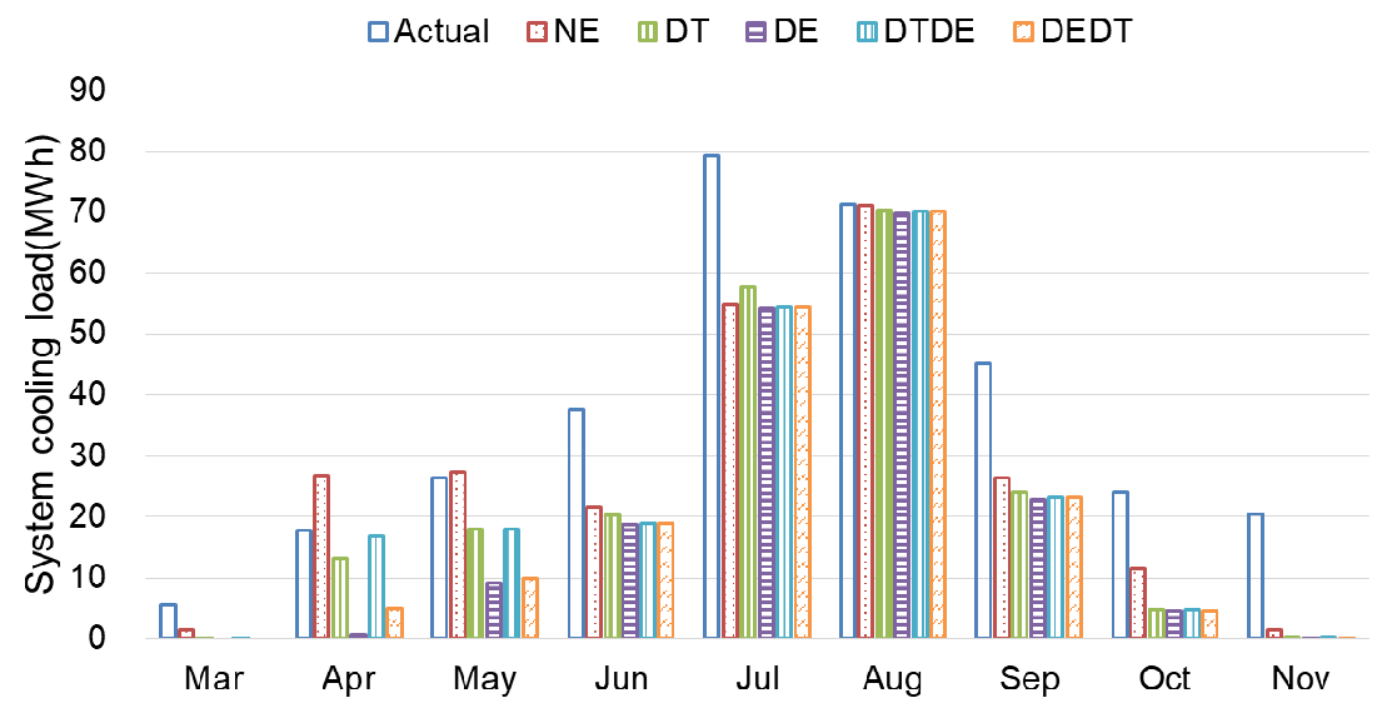

Figure 10. System cooling loads by actual operation and control types.

In summer, the distribution of monthly system cooling loads was similar between control types. In July and August, free-cooling was rarely used in most economizer control types due to high temperature and humidity in Seoul, where the target building is located. Thus, the distribution of system cooling loads was almost the same, regardless of the different economizer control types. The actual system cooling loads were relatively high from June to August, and the OAF was roughly $4-30 \%$ more than the economizer control types. The system cooling loads of the DT control were higher than the NE control. This is because, in the DT control, the latent loads cannot be considered.

In the fall, the system cooling loads were relatively small in October and November. The system cooling loads for September and October were similar between the control types, excluding the NE control. The DE control had the lowest cooling loads of 27.3 MWh. The actual building recorded 
89.7 MWh, and the NE control represented 39.3 MWh of the cooling loads during the fall. The DE control showed roughly $31 \%$ less cooling energy than the NE control and $67 \%$ less than the actual operation.

In summary, the system cooling loads of the case study building were investigated for nine months except winter. The DT control type had the highest system cooling loads of four control types. Table 5 shows the system cooling loads by the economizer control methods and the energy-saving ratios compared to actual building data and the NE control. The actual operation of the hospital building consumed more cooling energy than other economizer control types. Table 5 shows that the system cooling loads in actual case-building operations were $328 \mathrm{MWh}$ for cooling seasons (March to November). When comparing to all economizer control types, the actual operation consumed $36-45 \%$ more cooling energy. Moreover, compared to the NE control method, the potential cooling energy savings were up to $14 \%$ for the DT control, $25 \%$ for the DE control, $15 \%$ for the DTDE control, and $23 \%$ for the DEDT control. In a comparison between the DT control and the DTDE control, the system cooling loads of the DTDE control were 3 MWh lower than the DT control. Since outdoor air has high humidity around summer, the DTDE control could work effectively using high limit control of enthalpy than the DT control. Similarly, the DEDT control was roughly 6 MWh higher than the DE control. In the case of the DEDT control, it should be operated at the minimum OAF due to the high limit of the DT control where the maximum OAF should be operated in the DE control. In a comparison of the total cooling loads using optimal OAFs in economizer systems, the control types of the DE series (i.e., DE, DEDT) were the superior methods to the DT control type series (i.e., DT, DTDE). The DE control showed $13.9 \%$ less energy use in cooling systems than the DT controls, and the DEDT control used $10.0 \%$ less energy than the DTDE control in cooling coils.

Table 5. Total system cooling loads and estimated energy savings of economizer control types.

\begin{tabular}{ccccccc}
\hline & Actual & NE & DT & DE & DTDE & DEDT \\
\hline System cooling loads (MWh) & 328 & 242 & 209 & 180 & 206 & 186 \\
Savings (with Actual) $(\%)$ & - & 26 & 36 & 45 & 37 & 43 \\
Savings (with NE) $(\%)$ & -36 & - & 14 & 25 & 15 & 23 \\
\hline
\end{tabular}

\subsection{System Cooling Loads and Energy Savings Potential by Control Types in AHUs}

In the case study building, four AHUs (i.e., AHU 1-4) were operated based on building orientations. The interior and exterior environmental differences in thermal zones, such as different outdoor temperatures, heat gains, window-to-wall ratios, space programs, and occupancy rates in the patient rooms, make the discrepancies in system cooling loads. Therefore, this chapter investigated all four AHUs system loads to analyze the cooling system performance and energy savings potential of economizer control types.

Figure 11 shows the system cooling loads and energy-saving ratios under optimal OAF operations in each AHU. The energy savings of AHUs were calculated based on the comparison between the actual operation and economizer control types. The result of AHU 1 was already represented in Sections 4.2 and 4.3. In terms of the details of AHU 2, the actual system cooling load from the case building was $314 \mathrm{MWh}$, and the NE control used $201 \mathrm{MWh}$. In the result of control types, the system load in the DT driving was $171 \mathrm{MWh}$, and the DE control was $150 \mathrm{MWh}$. The DTDE control and the DEDT control showed $173 \mathrm{MWh}$ and $155 \mathrm{MWh}$, respectively. The cooling energy use of AHU 2 demonstrated that the actual building wasted a great deal due to excessive external air introduction in AHU system driving. Therefore, if the building reduces immoderate OAF and operates the HVAC systems based on control types, a huge amount of cooling energy will be saved in AHU 2. In cases of driving with the DT, DE, DTDE and DEDT controls, the potential energy savings were expected up to $46 \%, 52 \%, 45 \%$, and $51 \%$, respectively, compared to actual building's operation. When compared to the NE control in AHU 2, the expectations of energy savings were $15 \%$ for the DT, $25 \%$ for the DE, $14 \%$ for the DTDE, and $23 \%$ for the DEDT control, separately. As for AHU 3, the system cooling loads were $288 \mathrm{MWh}$ for the actual building, $361 \mathrm{MWh}$ for the NE control, and $303 \mathrm{MWh}$ for the DT control, $262 \mathrm{MWh}$ for the DE control, 
300 MWh for the DTDE control and 265 MWh for the DEDT control. Compared to the DE control that consumed the lowest cooling energy, the NE control and actual building consumed $38 \%$ and $10 \%$ more energies, respectively. The AHU 3 in actual operation had the most similar results with the four economizer controls. This indicates that AHU 3 operated the OAF most efficiently compared to AHU 1, AHU 2, and AHU 4. The AHU 4 in the actual building used 148-170 MWh more cooling energy than all control types, which was also 136 MWh more than the NE control. The result of AHU 4 showed the largest potential for cooling energy conservation when applying the economizer control methods with optimal OAFs.

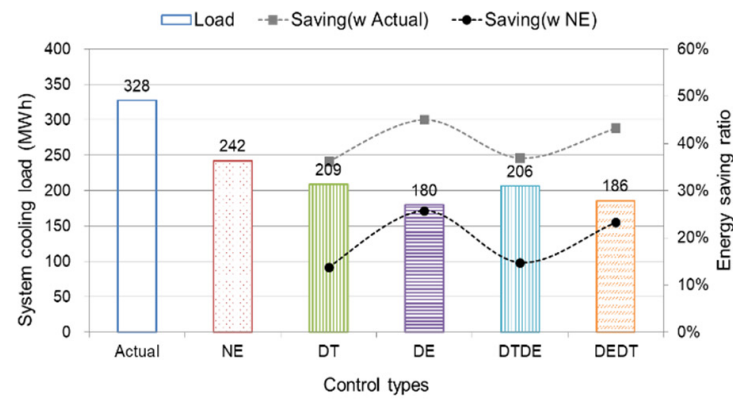

(a) AHU 1

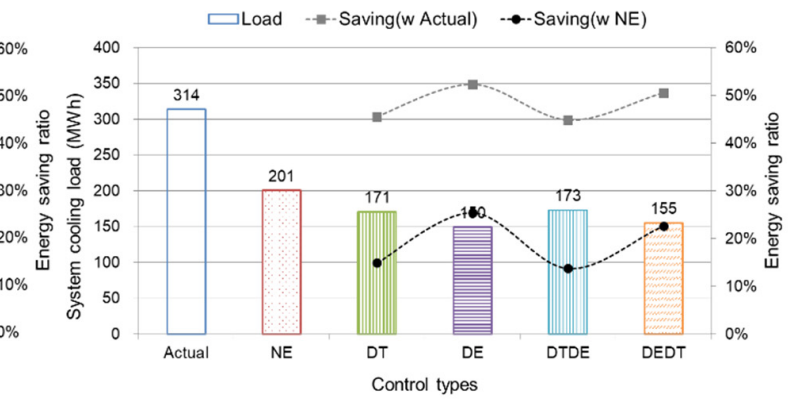

(b) AHU 2

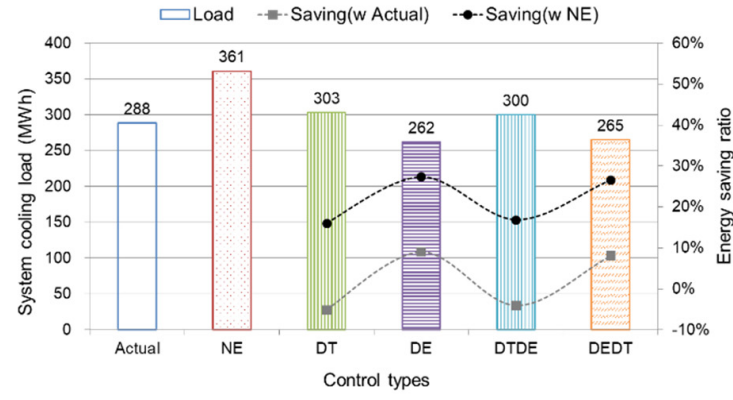

(c) AHU 3

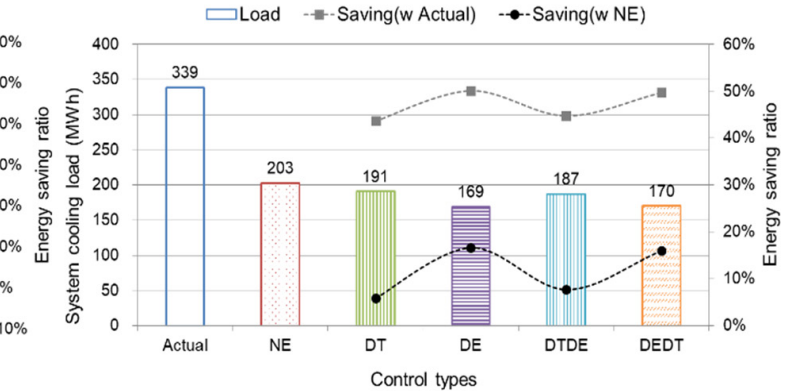

(d) AHU 4

Figure 11. System cooling loads of the AHUs by control types and energy-saving ratio.

Table 6 represent normalized system cooling loads and savings of economizer control types using optimal OAFs in the hospital. The normalized energy use can allow us to accurately compare energy usage per unit area, because four AHUs have different thermal zone areas. The energy-saving result represented that AHU 3 was the most efficiently operated among AHUs. AHU 3 used $5 \mathrm{kWh} / \mathrm{m}^{2}$ less energy than the DT control. However, the other three AHUs showed much more cooling energy use compared to all economizer control types. This implies that AHU 1, AHU 2, and AHU 4 have substantial energy waste as well as savings potential from HVAC system operations using the control types with optimal OAFs. Above all, the results indicate that the operation of the DE control types (i.e., DE, DEDT) was the most energy-saving approach in the target building. It could reduce about $17-27 \%$ cooling loads compared to the NE operation. 
Table 6. Normalized system cooling loads and savings potential of economizer control types.

\begin{tabular}{cccccccc}
\hline & AHU & Actual & NE & DT & DE & DTDE & DEDT \\
\hline \multirow{3}{*}{$\begin{array}{c}\text { System cooling loads } \\
\left(\mathrm{kWh} / \mathrm{m}^{2}\right)\end{array}$} & AHU 1 & 123.8 & 91.5 & 78.9 & 68.0 & 78.0 & 70.2 \\
& AHU 2 & 137.4 & 87.9 & 74.8 & 65.5 & 75.8 & 68.0 \\
& AHU 3 & 142.3 & 178.1 & 149.5 & 129.4 & 148.1 & 130.7 \\
& AHU 4 & 117.6 & 70.4 & 66.3 & 58.7 & 65.0 & 59.2 \\
\multirow{3}{*}{ Savings (with Actual) (\%) } & AHU 1 & - & 26 & 36 & 45 & 37 & 43 \\
& AHU 2 & - & 36 & 46 & 52 & 45 & 51 \\
& AHU 3 & - & -25 & -5 & 9 & -4 & 8 \\
\multirow{2}{*}{ Savings (with NE) (\%) } & AHU 4 & - & 40 & 44 & 50 & 45 & 50 \\
& AHU 1 & -35 & - & 14 & 26 & 15 & 23 \\
& AHU 2 & -56 & - & 15 & 25 & 14 & 23 \\
& AHU 3 & 20 & - & 16 & 27 & 17 & 27 \\
\hline
\end{tabular}

The results of this field study provide significant implications that the actual operations of the hospital were very different from the initial expectations of this study. Therefore, efforts are needed to reduce the gap between the estimated energy performance and the actual operating performance of HVAC systems in the buildings. This study would offer a milestone to understand why careful operations using economizer controls are essential with optimal OAFs in the hospital to optimize system operations.

\section{Discussion}

Seasonally, of the control types, the differential enthalpy (DE) control showed the best fit for cooling energy conservation in spring. It can save six times more cooling energy than the no economizer (NE) control from March to May. In terms of the DE control method, it had a large effect in spring, but no significant impact during the summer and fall compared to the other control types. DT control type was about 1.7 times more efficient in cooling loads than the NE control in spring. Contrastively, the evaluations in the summer showed that the DT control represented more cooling energy than the NE control, because outdoor air was introduced without considering latent loads in the DT control [21,33]. The case study building was more energy-efficient than the DT control in summer, and it is desirable to determine the outdoor air fraction in consideration of the indoor $\mathrm{CO}_{2}$ concentration. In addition, in the fall, DT driving can save about $30 \%$ of system cooling loads compared to the NE control. The DTDE and DEDT controls were carried out to confirm that these controls can additionally contribute to energy saving quantitatively as combination controls. It was found that the DTDE control saved only about $1-2 \%$ more energy than the DT control. Therefore, from the conventional DT and combination models, there is a need for developing improved DT control strategies. Moreover, recently, there have been many attempts to advance building system controls using a variety of energy management platforms, such as Model Predictive Control (MPC) [34], Internet of Things (IoT) technologies [35], event-triggered mechanism [36], Supervisory Control and Data Acquisition System (SCADA) [37]. The SCADA system can integrate various types of building information from several technologies in buildings (i.e., control of ventilation, temperature, illumination). The combination with the advanced monitoring and control approaches in HVAC systems will help improve the economizer controls in the existing buildings and provide more potential to reduce building energy by realistically interacting with building space and building environment.

\section{Conclusions}

This study investigated the economizer control types as an energy conservation measure for AHU operations in the hospital in Seoul, Korea. Four economizer control types (i.e., DT, DE, DTDE, DEDT) were selected for the performance estimations and were studied to provide OAF-focused observations. Based on the optimal OAF calculations of economizer control types, the system cooling 
loads and savings potential were estimated in cooling seasons (i.e., spring, summer, fall). In the 2016 AHU driving data, in May and September, the economizer had the highest free-cooling potential. The calculations of the optimal OAF showed that the OAF of all control types is different according to the seasonal changes from March to November.

The DE control showed the lowest cooling energy use among all control types. This indicates that the DE control was the most superior control type for cooling seasons in the hospital. The normalized energy savings potential was $6-14 \%$ for the DT control, $17-27 \%$ for the DE control, $8-17 \%$ for the DTDE control, and $16-27 \%$ for the DEDT control compared to the NE control.

In this study, by comparing the cooling coil loads of actual operation to each economizer control type, the amount of potential energy savings of the case study building was quantitatively examined through four economizer control models. In addition, the result of this study is significant in developing an energy-efficient HVAC driving plan by investigating actual driving data for spring, summer, and fall, when economizers can be applied during the year in hot-humid climate regions.

Therefore, the result of this study would provide a better understanding of economizer control types to improve building energy efficiency in HVAC systems. Moreover, to develop more effective HVAC operation methods in actual buildings, it is necessary to continuously study the operation and maintenance $(\mathrm{O} \& \mathrm{M})$ of economizer controls to prevent the failure of actual operations in commercial buildings.

Author Contributions: Conceptualization, G.H.; methodology and writing—original draft preparation, G.H.; writing - review and editing, G.H. and C.K.; visualization, C.K. and J.H. All authors have read and agreed to the published version of the manuscript.

Funding: This work was supported by the National Research Foundation of Korea(NRF) grant funded by the Korea government(MSIT) (No. 2020R1C1C1010801).

Acknowledgments: I would like to thank to facility managers of the hospital for cooperation of the data.

Conflicts of Interest: The authors declare no conflict of interest.

\section{Abbreviations}

$\begin{array}{ll}\text { AHU } & \text { Air handling unit } \\ \text { DE } & \text { Differential enthalpy } \\ \text { DT } & \text { Differential dry-bulb temperature } \\ \text { DEDT } & \text { Differential enthalpy and differential dry-bulb temperature } \\ \text { DTDE } & \text { Differential dry-bulb temperature and differential enthalpy } \\ \text { NE } & \text { No economizer } \\ \text { OAE } & \text { Outdoor air enthalpy } \\ \text { OAF } & \text { Outdoor air fraction } \\ \text { OAFC } & \text { Outdoor air fraction calculation } \\ \text { RAE } & \text { Return air enthalpy } \\ \text { SAE } & \text { Supply air enthalpy } \\ \text { TMA } & \text { Mixed air temperature } \\ \text { TOA } & \text { Outdoor air temperature } \\ \text { TRA } & \text { Return air temperature } \\ \text { TSA } & \text { Supply air temperature } \\ \text { VAV } & \text { Variable Air Volume } \\ \text { Symbols } & \\ h & \text { enthalpy } \\ T & \text { temperature }\end{array}$




\section{References}

1. Korea Energy Economics Institute, Yearbook of Energy Statistics. Available online: http://www.keei.re.kr/ keei/download/YES2017.pdf (accessed on 29 April 2020).

2. Meng, Q.; Yan, X.; Ren, Q.; Adeli, H. Variable Air Volume Air-Conditioning Experiment System with Advanced Controls. Indoor Built Environ. 2016, 25, 114-127. [CrossRef]

3. IEA. Energy Efficiency Requirements in Building Codes: Policies for New Buildings; IEA: Paris, France, 2008; Available online: https://www.iea.org/reports/energy-efficiency-requirements-in-building-codes-policiesfor-new-buildings (accessed on 15 April 2020).

4. U.S. Department of Energy, 2011 Buildings Energy Data Book. Available online: https://ieer.org/wp/wpcontent/uploads/2012/03/DOE-2011-Buildings-Energy-DataBook-BEDB.pdf (accessed on 3 May 2020).

5. Cheon, S.H.; Kwak, Y.H.; Jang, C.Y.; Huh, J.H. Comparison with Energy Saving Potential of Similar AHU Control Strategie. J. Archit. Inst. Korea 2012, 32, 281-282.

6. Yang, Z.; Becerik-Gerber, B. The Coupled Effects of Personalized Occupancy Profile Based HVAC Schedules and Room Reassignment on Building Energy Use. Energy Build. 2014, 78, 113-122. [CrossRef]

7. Kim, W.; Katipamula, S. Development and Validation of an Intelligent Load Control Algorithm. Energy Build. 2017, 135, 62-73. [CrossRef]

8. Givoni, B. Effectiveness of Mass and Night Ventilation in Lowering the Indoor Daytime Temperatures. Part I: 1993 Experimental Periods. Energy Build. 1998, 28, 25-32. [CrossRef]

9. Shaviv, E.; Yezioro, A.; Capeluto, I.G. Thermal Mass and Night Ventilation as Passive Cooling Design Strategy. Renew. Energy 2001, 24, 445-452. [CrossRef]

10. Nassif, N.; Moujaes, S. A New Operating Strategy for Economizer Dampers of VAV System. Energy Build. 2008, 40, 289-299. [CrossRef]

11. Wang, G.; Song, L. Air Handling Unit Supply Air Temperature Optimal Control During Economizer Cycles. Energy Build. 2012, 49, 310-316. [CrossRef]

12. Kim, D.; Braun, J.E. Model Predictive Control for Supervising Multiple Rooftop unit Economizers to fully Leverage Free Cooling Energy Resource. Appl. Energy 2020, 275, 115324. [CrossRef]

13. Lee, K.P.; Chen, H.L. Analysis of Energy Saving Potential of Air-Side Free Cooling for Data Centers in Worldwide Climate Zones. Energy Build. 2013, 64, 103-112. [CrossRef]

14. ASHRAE. 2016 ASHRAE Handbook- HVAC Systems and Equipment; ASHRAE: Atlanta, GA, USA, 2016.

15. Bulut, H.; Aktacir, M.A. Determination of Free Cooling Potential: A Case Study for İstanbul, Turkey. Appl. Energy 2011, 88, 680-689. [CrossRef]

16. Sun, Z.; Wang, S.; Zhu, N. Model-based Optimal Control of Outdoor Air Flow Rate of an Air-Conditioning System with Primary Air-Handling Unit. Indoor Built Environ. 2011, 20, 626-637. [CrossRef]

17. Budaiwi, I.M. Energy Performance of the Economizer Cycle under Three Climatic Conditions in Saudi Arabia. Int. J. Ambient. Energy 2001, 22, 83-94. [CrossRef]

18. Faulkner, D.; Fisk, W.J.; Sullivan, D.P.; Lee, S.M. Ventilation Efficiencies and Thermal Comfort Results of a Desk-Edge-Mounted Task Ventilation System. Indoor Air Suppl. 2004, 14, 92-97. [CrossRef]

19. Yao, Y.; Wang, L. Energy Analysis on VAV System with Different Air-Side Economizers in China. Energy Build. 2010, 42, 1220-1230. [CrossRef]

20. Chowdhury, A.A.; Rasul, M.G.; Khan, M.M.K. Modelling and Analysis of Air-Cooled Reciprocating Chiller and Demand Energy Savings Using Passive Cooling. Appl. Therm. Eng. 2009, 29, 1825-1830. [CrossRef]

21. Son, J.E.; Lee, K.H. Cooling Energy Performance Analysis Depending on the Economizer Cycle Control Methods in an Office Building. Energy Build. 2016, 120, 45-57. [CrossRef]

22. Aktacir, M.A. Performance Evaluation of Different Air-Side Economizer Control Methods for Energy Efficient Building. J. Therm. Sci. Technol. 2012, 32, 19-30.

23. Nassif, N. Performance Analysis of Supply and Return Fans for HVAC Systems under Different Operating Strategies of Economizer Dampers. Energy Build. 2010, 42, 1026-1037. [CrossRef]

24. Ham, S.W.; Park, J.S.; Jeong, J.W. Optimum Supply Air Temperature Ranges of Various Air-Side Economizers in a Modular Data Center. Appl. Therm. Eng. 2015, 77, 163-179. [CrossRef]

25. Siriwardana, J.; Jayasekara, S.; Halgamuge, S.K. Potential of Air-Side Economizers for Data Center Cooling: A Case Study for Key Australian cities. Appl. Energy 2013, 104, 207-219. [CrossRef] 
26. Shehabi, A.; Ganguly, S.; Gundel, L.A.; Horvath, A.; Kirchstetter, T.W.; Lunden, M.M.; Tschudi, W.; Gadgil, A.J.; Nazaroff, W.W. Can Combining Economizers with Improved Filtration Save Energy and Protect Equipment in Data Centers? Build. Environ. 2010, 45, 718-726. [CrossRef]

27. Díaz, A.J.; Cáceres, R.; Torres, R.; Cardemil, J.M.; Silva-Llanca, L. Effect of Climate Conditions on the Thermodynamic Performance of a Data Center Cooling System under Water-Side Economization. Energy Build. 2020, 208. [CrossRef]

28. Li, B.; Wild, P.; Rowe, A. Free Cooling Potential of Air Economizer in Residential Houses in Canada. Build. Environ. 2020, 167. [CrossRef]

29. Zhang, J.; Fung, A.S.; Jhingan, S. Analysis and Feasibility Study of Residential Integrated Heat and Energy Recovery Ventilator with Built-In Economizer Using an Excel Spreadsheet Program. Energy Build. 2014, 75, 430-438. [CrossRef]

30. ASHRAE. Energy Standard for Buildings Except Low-Rise Residential Buildings; ASHRAE: Atlanta, GA, USA, 2013.

31. ASHRAE. Standard 170-2013. Ventilation of Health Care Facilities; ASHRAE: Atlanta, GA, USA, 2013.

32. Korean Standard, Rules on the Standards, etc. of Facilities in Buildings. Ministry of Land, Infrastructure, and Transport, Korea. 2013. Available online: http://www.law.go.kr (accessed on 29 April 2020).

33. Yiu, J.C.M.; Wang, S.W.; Yik, F.W.H. Assessment of Practical Applications of Outdoor Air Economizer in Hong Kong. Build. Serv. Eng. Res. Technol. 2000, 21, 187-198. [CrossRef]

34. Hazyuk, I.; Ghiaus, C.; Penhouet, D. Optimal Temperature Control of Intermittently Heated Buildings Using Model Predictive Control: Part II-Control Algorithm. Build. Environ. 2012, 51, 388-394. [CrossRef]

35. Carli, R.; Cavone, G.; Ben Othman, S.; Dotoli, M. IoT Based Architecture for Model Predictive Control of HVAC Systems in Smart Buildings. Sensors 2020, 20, 781. [CrossRef]

36. Xu, Z.; Hu, G.; Spanos, C.J.; Schiavon, S. PMV-Based Event-Triggered Mechanism for Building Energy Management under Uncertainties. Energy Build. 2017, 152, 73-85. [CrossRef]

37. Figueiredo, J.; Sá Da Costa, J. A SCADA System for Energy Management in Intelligent Buildings. Energy Build. 2012, 49, 85-98. [CrossRef] 